\title{
Carbimazole and exercise tolerance in chronic airflow obstruction
}

\author{
RJA BUTLAND, JA PANG, DM GEDDES
}

From Brompton Hospital, London

ABSTRACT Ten patients with severe dyspnoea and chronic airflow obstruction entered a randomised double-blind crossover trial comparing the effect of carbimazole $80 \mathrm{mg}$ daily for two months with that of placebo. Assessment of thyroid function, lung function, and exercise tolerance was performed monthly. The mean free thyroxine index after two months of carbimazole was significantly lower at $64 \cdot 1( \pm 10 \cdot 5, \mathrm{SEM})$ than the $89 \cdot 1( \pm 3 \cdot 8)$ while on placebo. Serum tri-iodothyronine was reduced and thyroid stimulating hormone raised while on the active drug. There was no significant difference in the 12-minute walking distance (TMD), the rating of perceived exertion during the TMD, the oxygen cost score, the dyspnoea grade, the resting arterialised capillary blood gas tensions or the resting minute ventilation. During a progressive exercise test to exhaustion on a cycle ergometer, there was no significant difference in the minute ventilation, heart rate, blood gas tensions at exhaustion, or the total work done. There were no symptoms or signs of hypothyroidism. Lung function $\left(\mathrm{FEV}_{1}, \mathrm{FVC}, \mathrm{TLC}, \mathrm{KCO}\right)$ was unchanged. Thus a $28 \%$ reduction in the free thyroxine index produced no symptomatic or objective benefit in exercise tolerance in patients with severe airflow obstruction. These results provide no support for the use of carbimazole in chronic airflow obstruction.

The induction of hypothyroidism with radioiodine has been used in attempts to alleviate the dyspnoea of chronic airflow obstruction. ${ }^{1-5}$ These studies claimed benefit but were uncontrolled and tended to produce the clinical features of myxoedema.

In a patient with emphysema and coincidental myxoedema, thyroxine replacement was associated with a reduction in exercise tolerance and an increase in ventilation. ${ }^{6}$ Changes in ventilation are probably the mechanism by which anti-thyroid treatment improves dyspnoea. Patients with thyrotoxicosis have a high minute ventilation and patients with myxoedema a low minute ventilation. These changes are present both at rest and on exercise, and are a reflection of changes in metabolic rate, ventilatory drive, and muscular weakness. ${ }^{7-14}$ It might thus be possible to reduce ventilation and improve exercise tolerance by a modest reduction in thyroid function.

We have therefore conducted a double-blind placebo controlled trial of carbimazole in patients with chronic airflow obstruction in an attempt to improve exercise tolerance. We reduced thyroid function but not to a degree that would produce hypothyroid symptoms.

Address for reprint requests: Dr RJA Butland, Department of Thoracic Medicine, New Cross Hospital, Avonley Road, London SE14 5ER.

\section{Methods}

Ten patients, mean age 60 years $(\mathrm{SD}=11$ years), whose major symptom was breathlessness caused by irreversible chronic airflow obstruction $\left(\mathrm{FEV}_{1}<11\right)$ were studied. Patients with evidence of other lung disease, thyroid disease, serious disease of other organ systems, or a $\mathrm{PaCO}_{2}$ above $6.0 \mathrm{kPa}$ were excluded. Arterial blood gas tensions were measured when the patient was clinically stable, breathing air, and on inhaled bronchodilators (salbutamol $200 \mu \mathrm{g}$ qds). At the time of entry into the trial all patients were in a stable clinical and functional state and no change in drug therapy (except for courses of antibiotics) was made during the trial.

A randomised double-blind crossover trial between carbimazole (Neomercazole, Nicholas Laboratories) $80 \mathrm{mg}$ daily and placebo of identical appearance was performed. The patients took carbimazole or placebo for two months, then placebo for one month to allow any reduction in thyroid function to recover and finally the crossover drug for two months. Assessment of thyroid function, lung function, and exercise tolerance was performed, always in the morning. Assessment was made at the end of each month.

Transfer coefficient (KCO) was measured by the 
carbon monoxide/helium single breath test ${ }^{15}$ on a resparameter (PK Morgan) and forced expiratory volume in one second $\left(F E V_{1}\right)$ and forced vital capacity (FVC) on a dry spirometer (Ohio). Results were expressed as a percentage of normal values. ${ }^{16}$ The distance walked in 12 minutes was measured ${ }^{17}$ and the strain of this exercise scored on Borg's rating of perceived exertion. ${ }^{18}$

In the progressive exercise test patients were seated on a cycle ergometer (AM 368 Siemens) for five minutes before resting values were taken. Inspiratory minute ventilation was measured on a dry gas meter (Parkinson-Cowan), heart rate counted from an electrocardiogram and resting and maximal exercise arterialised capillary ear lobe blood gas tensions measured with a blood gas analyser (165, Corning Medical). The external work load was increased by 100 kilopond metres $/ \mathrm{min}$ (16.4 watts) every minute until exhaustion. All patients had a practice exercise test and two practice walking tests before entry to the trial. Subjective assessment of exercise tolerance was made by dyspnoea grade and by oxygen cost diagram. ${ }^{19}$ Thyroid hormone levels were measured by radioimmunoassay.

The tests were always performed in the order described above and 20 minutes rest was enforced between the walking and cycle tests.

\section{Results}

Mean values are shown in the table. There was no significant difference between the two placebo months for any of the variables measured. The free thyroxine index (FTI) after two months of carbimazole was reduced by $28 \%$ from $89 \cdot 1$ to $64 \cdot 1$. Serum tri-iodothyronine $\left(\mathrm{T}_{3}\right)$ was also significantly reduced and thyroid stimulating hormone (TSH) raised. There was no associated change in exercise performance, whether assessed subjectively (dyspnoea grade, oxygen cost diagram, and rating of perceived exertion) or objectively (by submaximal (walking test) or maximal (cycle ergometer) exercise tests). Arterial blood gas tensions and minute ventilation were not altered by carbimazole either at rest or on exercise. After one month of carbimazole the only significant change was a fall in total $\mathrm{T}_{3}$.

Mean values $( \pm S E)$ for exercise testing on consecutive months of the trial, regardless of whether carbimazole or placebo were being taken, are shown (figure). In the progressive exercise test, at exhaustion total work done, heart rate, and minute ventilation fell progressively $(p<0.01)$. In contrast the 12-minute distance remained steady but the rating of perceived exertion gradually increased. There were no significant changes in lung function or blood gas tensions.

Table Summary of results (mean values)

\begin{tabular}{|c|c|c|c|c|c|c|c|}
\hline & & \multicolumn{2}{|l|}{ Placebo } & \multicolumn{4}{|c|}{ Carbimazole } \\
\hline & & \multirow[b]{2}{*}{ Mean } & \multirow[b]{2}{*}{$S D$} & \multicolumn{2}{|c|}{ One month } & \multicolumn{2}{|c|}{ Two months } \\
\hline & & & & Mean & $S D$ & Mean & $S D$ \\
\hline \multirow{2}{*}{\multicolumn{2}{|c|}{$\begin{array}{l}\text { Free thyroxine index } \\
\text { Total } T(n m o l / 1)\end{array}$}} & $89 \cdot 1$ & $16 \cdot 9$ & $78 \cdot 6$ & $16 \cdot 3$ & $64 \cdot 1$ & $33 \cdot 1 *$ \\
\hline & & $2 \cdot 30$ & $0 \cdot 23$ & $2 \cdot 10$ & $0 \cdot 25^{*}$ & $2 \cdot 01$ & $0 \cdot 43 *$ \\
\hline \multicolumn{2}{|l|}{ TSH $(\mathrm{mu} / \mathrm{l})$} & $2 \cdot 7$ & $1 \cdot 2$ & $3 \cdot 4$ & $2 \cdot 5$ & $14 \cdot 3$ & $19 \cdot 2^{*}$ \\
\hline \multicolumn{2}{|l|}{$\mathrm{FEV}_{1}(\%)$} & $24 \cdot 2$ & $9 \cdot \overline{2}$ & $24 \cdot 2$ & $9 \cdot 6$ & $23 \cdot 4$ & $8 \cdot 4$ \\
\hline \multicolumn{2}{|l|}{ FVC $(\%)$} & $70 \cdot 7$ & $22 \cdot 1$ & $66 \cdot 7$ & $20 \cdot 5$ & $69 \cdot 9$ & $21 \cdot 1$ \\
\hline \multicolumn{2}{|l|}{$\mathrm{KCO}(\%)$} & $35 \cdot 1$ & $13 \cdot 8$ & $33 \cdot 3$ & $12 \cdot 4$ & $36 \cdot 3$ & $13 \cdot 1$ \\
\hline \multicolumn{2}{|l|}{ 12-minute walking distance $(\mathrm{m})$} & 719 & 180 & 733 & 206 & 705 & 221 \\
\hline \multicolumn{2}{|l|}{ RPE' (Borg units) } & $13 \cdot 5$ & $1 \cdot 7$ & $13 \cdot 7$ & $2 \cdot 0$ & $13 \cdot 3$ & $1 \cdot 6$ \\
\hline \multicolumn{2}{|l|}{ Oxygen cost score } & $51 \cdot 8$ & $10 \cdot 7$ & $48 \cdot 5$ & $11 \cdot 9$ & $52 \cdot 5$ & $12 \cdot 2$ \\
\hline \multicolumn{2}{|l|}{ Dyspnoea grade } & $3 \cdot 7$ & 0.6 & $3 \cdot 5$ & 0.9 & $3 \cdot 5$ & 0.9 \\
\hline \multicolumn{2}{|l|}{ Rest $\mathrm{PaO}_{2}(\mathrm{kPa})$} & $9 \cdot 26$ & $1 \cdot 14$ & $9 \cdot 33$ & $1 \cdot 35$ & $9 \cdot 79$ & $1 \cdot 25$ \\
\hline \multicolumn{2}{|l|}{ Rest $\mathrm{PaCO}_{2}(\mathrm{kPa})$} & $4 \cdot 78$ & 0.68 & $4 \cdot 67$ & 0.90 & $4 \cdot 47$ & 0.75 \\
\hline \multicolumn{2}{|l|}{ Exercise $\mathrm{PaO}_{2}(\mathrm{kPa})$} & $7 \cdot 95$ & $1 \cdot 30$ & $7 \cdot 88$ & $1 \cdot 22$ & $8 \cdot 10$ & 1.05 \\
\hline \multicolumn{2}{|l|}{ Exercise $\mathrm{PaCO}_{2}(\mathrm{kPa})$} & $5 \cdot 35$ & 1.06 & $5 \cdot 36$ & 0.76 & $5 \cdot 17$ & 0.60 \\
\hline \multirow[t]{2}{*}{ Work done (kpm) } & & 519 & 327 & 453 & 272 & 472 & 299 \\
\hline & $\begin{array}{l}\text { Work load } \\
(\mathrm{kpm} / \mathrm{min})\end{array}$ & & & & & & \\
\hline Minute ) & 0 & $12 \cdot 70$ & $2 \cdot 46$ & $12 \cdot 49$ & $3 \cdot 39$ & 11.99 & $2 \cdot 36$ \\
\hline ventilation ) & 100 & $17 \cdot 14$ & $4 \cdot 30$ & $17 \cdot 42$ & 3.97 & $17 \cdot 1$ & $4 \cdot 93$ \\
\hline$(1 / \mathrm{min}) \quad)$ & 200 & 19.94 & $4 \cdot 32$ & $20 \cdot 04^{2}$ & $6 \cdot 12$ & $21 \cdot 17^{3}$ & $6 \cdot 52$ \\
\hline Heart & 0 & $82 \cdot 8$ & $11 \cdot 0$ & 92.6 & 21.9 & $89 \cdot 2$ & $18 \cdot 4$ \\
\hline rate ) & 100 & $95 \cdot 2$ & $13 \cdot 2$ & $106 \cdot 2$ & $24 \cdot 5$ & 99.8 & $16 \cdot 7$ \\
\hline (beats/min)) & 200 & $99 \cdot 8$ & 11.8 & $112 \cdot 9^{2}$ & $25 \cdot 4$ & $109 \cdot 7^{3}$ & $18 \cdot 5$ \\
\hline
\end{tabular}

For placebo $n=20$, for carbimazole $n=10$

${ }^{1} \mathrm{RPE}=$ rating of perceived exertion.

$2 \mathrm{n}=7$

$3 \mathrm{n}=6$

*Differs significantly from placebo using Student's $t$ test. ${ }^{*} p<0.05 * * p<0.001$ 


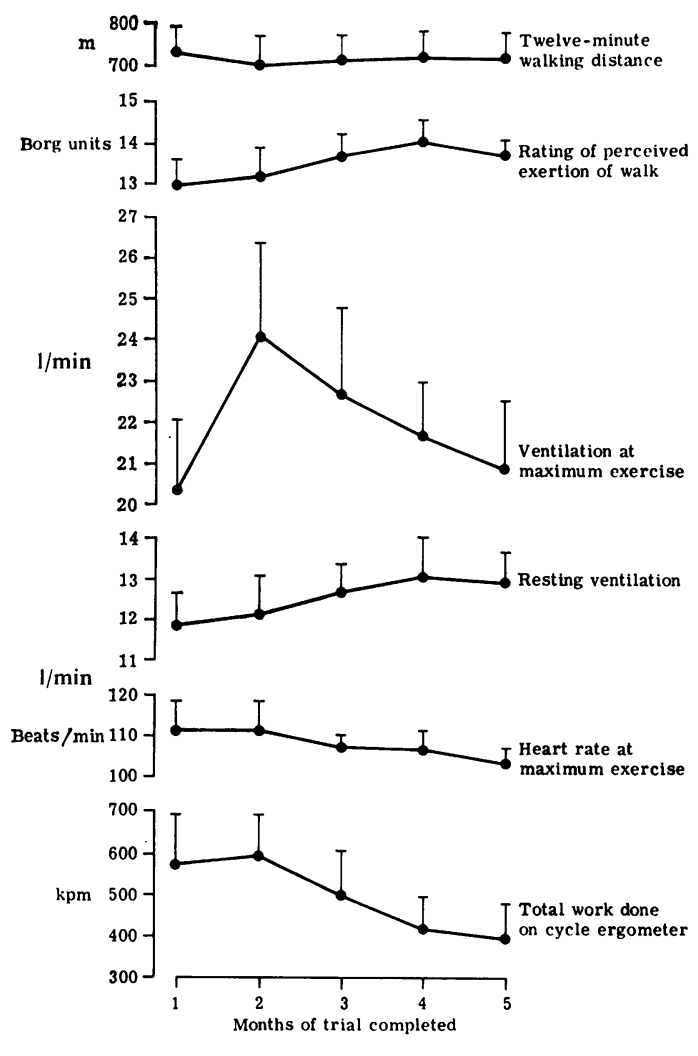

Figure Mean values ( $\pm S E$ ) for exercise testing on consecutive months of the trial.

\section{Discussion}

This study demonstrated that a $28 \%$ reduction in the mean FTI produced no symptomatic or objective change in exercise tolerance in patients with severe chronic airflow obstruction. There was no benefit in the four patients whose FTI fell into the hypothyroid range.

The group of patients studied may not represent a cross-section of chronic airflow obstruction as we excluded hypercapnic subjects because ventilatory drive is reduced in hypothyroidism ${ }^{11} 1314$ and such a reduction could be detrimental to patients with hypercapnic respiratory failure. Also all the patients had radiological evidence of emphysema (overinflation). However, patients with emphysema hyperventilate during exercise as compared with chronic bronchitics matched for a similar degree of airflow obstruction ${ }^{20}$ and might, therefore, be expected to benefit more from a lower ventilatory rate.

The patients received carbimazole for only two months. While it is possible that longer treatment might produce an improvement in exercise tolerance, this is unlikely as changes in metabolic rate follow changes in circulating hormone levels within days. ${ }^{21}$ Similarly we cannot exclude the possiblity that higher doses of carbimazole producing greater changes in thyroid status might be beneficial. However, more aggressive treatment would be likely to produce clinical myxoedema and consequent deterioration in the patients' quality of life.

It is well established that thyroid status may influence dyspnoea. ${ }^{89}$ These results suggest that reduction of thyroid hormone levels without the induction of hypothyroidism does not improve dyspnoea or exercise tolerance and therefore provide no support for the use of carbimazole in chronic airflow obstruction.

As carbimazole and placebo were similar in this study, we had a rare opportunity to study changes in exercise performance with time. Although there was no change in lung function during the trial, the exercise tolerance deteriorated significantly. The fall in maximum heart rate suggests that this deterioration was caused at least in part by decreasing motivation. These sequential changes, independent of treatment or lung function, are a potential source of bias in uncontrolled trials.

We are indebted to Derek Cramer and the technicians of the lung function laboratory, and to Nicholas Pharmaceuticals for assistance.

\section{References}

${ }^{1}$ Beren BA, Mandell HN. Radioactive iodine for chronic lung disease. J Clin Invest 1954;33:917.

${ }^{2}$ Hurst A, Levine MH. Radio-iodine in the treatment of pulmonary emphysema. Rocky Mt Med J 1955;52: 129-31.

${ }^{3}$ Hurst A, Levine MH, Rich DR. Radioactive lodine in the management of patients with severe pulmonary emphysema. Ann Allergy 1955;13:393-7.

${ }^{4}$ Levine MH, Hurst A. Radio-iodine in pulmonary emphysema. Rocky Mt Med J 1963;60:35-6.

${ }^{5}$ Bernard E, Israel L, Vincent J, Garmain B, Coby J. $J$ Franc Med Chirurg Thorac 1965;19:703-11.

${ }^{6}$ Butland RJA, Pang JA, Geddes DM. Thyroxine and dyspnoea in emphysema. Br J Dis Chest 1981 ;75:96-8.

' Bishop JM, Donald KW, Wade OL. Circulatory dynamics at rest and on exercise in hyperkinetic states. Clin Sci $1955 ; 14: 329-60$.

${ }^{8}$ Stein M, Kimbel P, Johnson RL. Pulmonary function in hyperthyroidism. J Clin Invest 1961 ;40:348-63.

${ }^{9}$ Massey DG, Becklake MR, McKenzie JM, Bates DV. Circulatory and ventilatory response to exercise in thyrotoxicosis. N Engl J Med 1967;276:1104-12.

10 Zwillich CW, Matthay M, Potts DE, Adler R, Hofeldt F, Weil JW. Thyrotoxicosis: Comparison of effects of thyroid ablation and beta-adrenergic blockade on 
metabolic rate and ventilatory control. J Clin Endocrinol Metab 1978;46:491-500.

11 Wilson WR, Bedell GN. The pulmonary abnormalities in myxedema. J Clin Invest 1960;39:42-55.

12 Burack R, Edwards RHT, Green M, Jones NL. The response to exercise before and after treatment of myxoedema with thyroxine. J Pharmacol Exp Ther 1971; 176:212-9.

${ }^{13}$ Massumi RA, Winnacker JL. Severe depression of the respiratory center in myxedema. Am J Med 1964;36: 876-82.

${ }^{14}$ Zwillich CW, Pierson DJ, Hofeldt FD, Lutkin EG. Ventilatory control in myxedema and hypothyroidism. $N$ Engl J Med 1975;292:662-5.

15 Ogilvie CM, Forster RE, Blakemore WS, Morton JW. A standardised breath holding technique for the clinical measurement of the diffusing capacity of the lung for carbon monoxide. J Clin Invest 1957;36:1-7.
${ }^{16}$ Cotes JE. Lung function: assessment and application in medicine. Third edition. Oxford: Blackwell Scientific Publications, 1975.

17 McGavin CR, Gupta SP, McHardy GJR. Twelve-minute walking test for assessing disability in chronic bronchitis. Br Med J 1976;1:822-3.

${ }^{18}$ Borg G. Perceived exertion as an indicator of somatic stress. Scand J Rehabil Med 1970;2:92-8.

19 McGavin CR, Artvinli M, Naoe H, McHardy GJR. Dyspnoea, disability and distance walked: comparison of estimates of exercise performance in respiratory disease. Br Med J 1978;2:241-3.

20 Jones NL. Pulmonary gas exchange during exercise in patients with chronic airway obstruction. Clin Sci 1966; $31: 39-49$.

21 Nordqvist P, Dhuner KG, Stenberg K, Örndabl G. Myxoedema coma and $\mathrm{CO}_{2}$ retention. Acta Med Scand $1960 ; 166: 189-94$. 